\title{
ÖDEMIŞ-BOZDAĞ YOLU, PAŞA ÇEŞMESI
}

Hasan Uçar ${ }^{1}$

\section{Özet}

Askeri yönüyle olduğu gibi siyasi yönüyle de ön plana çıkan Kazım Dirik, valilik yaptığı dönemlerde imar faaliyetlerine önem vermiş, köy kalkınması için çeşitli çalışmalar yapmıştır. İzmir valiliği döneminde yol, cadde ve köprü yapımına önem veren vali, açtırdığı yollar üzerine çok sayıda çeşme inşa ettirmiştir. Vali Kazım Dirik tarafından inşa ettirilen Ödemiş-Bozdağ yolu üzerindeki Paşa Çeşmesi, mimari özellikleri yanı sıra anısal değeri ile de Cumhuriyet dönemi çeşme yapıları arasında yerini almıştır.

Anahtar kelimeler: İzmir, Ödemiş, Paşa Çeşmesi, Vali Kazım Dirik, Cumhuriyet dönemi çeşme, Kütahya çinisi.

\section{Abstract}

\section{Pasha Fountain on the Road from Ödemiş to Bozdağ}

Kazım Dirik as the Governor of İzmir, had emphasized the construction and development activities in the villages. In that period, the fountains were built on the roads and avenues during the construction of roads, avenues and bridges. One of the fountains is Pasha Fountain that was built in that period on the road from Ödemiş to Bozdağ. The Pasha fountain, illustrates monumental and architectural features of Republican Period and has special place between the fountains from the Republican Period.

Key words: İzmir, Ödemiş, Pasha Fountain, Governor Kazım Dirik, Republican Period, Tiles of Kütahya

\footnotetext{
${ }^{1}$ Uzm Dr. Ege Üniversitesi, Edebiyat Fakültesi, Sanat Tarihi Bölümü, Bornova-İZMIR
} 
I . Dünya Savaşı ve Kurtuluş Savaşı'nda başarılı bir asker olan Kazım Dirik, askerlikten ayrıldıktan sonra İzmir'de valilik yaptığı dönemde çeşitli imar faaliyeti çalıșmaları yapmış güçlü bir siyaset adamıdır. Valiliği döneminde birçok köy ve kasabaya ulaşımı sağlayan yolların açılmasına önem veren Kazım Dirik açtırdığ 1 yollara anı olarak birer çeşme de inşa ettirerek yolcuların susuzluğunun giderilmesini de sağlamıştır. Ödemiş-Bozdağ yolu üzerindeki Paşa Çeşmesi, BayındırTire-Aydın yolu üzerindeki Cumhuriyet Çeşmesi, Tire-Çamköy-Germencik yolu üzerindeki Cumhuriyet Çeşmesi ve Tire-Selçuk yolu üzerindeki Çavuş Çeşmesi Kazım Dirik tarafından yaptırılan çeşmelerden birkaçıdır. İşlevselliği açısından hayati öneme sahip olan bu çeşmeler yeni kurulan Cumhuriyet'in anısına yapılmaları ve döneminin mimari ve süsleme özelliklerini yansıtmaları açısından kültür mirasımız içerisinde büyük önem taşımaktadır. Biz de bu yazımızda, mimari olarak küçük boyutlu olmasına rağmen, döneminin özelliklerini bütünüyle yansıtan bu çeşmelerden biri olan ÖdemişBozdağ yolu üzerindeki Paşa Çeşmesi'ni fotoğrafları ve çizimleriyle tanıtmaya çalışacağız.

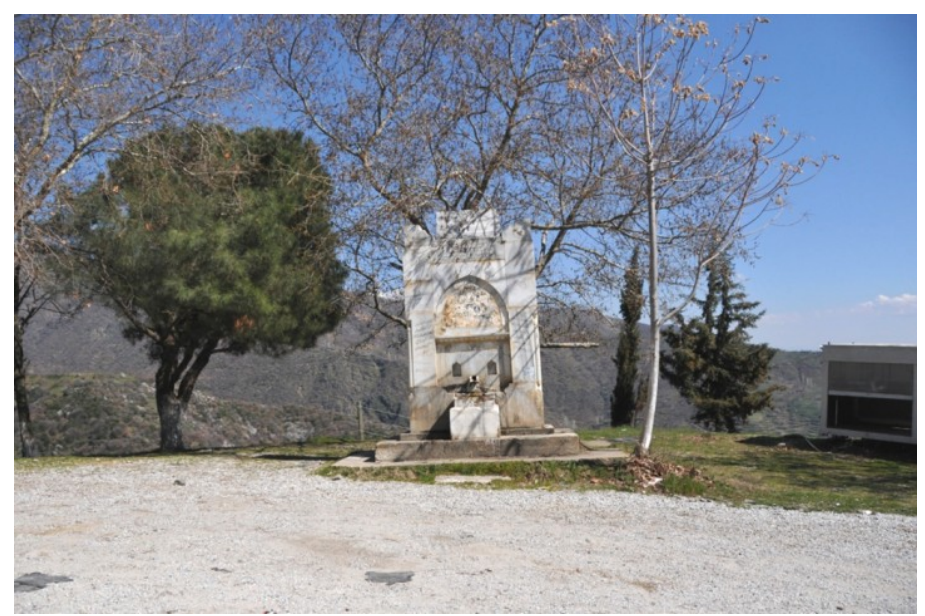

Res.1- Ödemiş-Bozdağ yolu Paşa Çeşmesi, genel görünüş.

Ödemiş-Bozdağ yolu üzerinde yer alan Paşa Çeşmesi, Birgi'den $11 \mathrm{~km}$. uzaklıktadır. Yol üzerinde bulunması nedeniyle herhangi bir yapıdan bağımsız olarak adeta bir meydan çeşmesi gibi tasarlanmıştır (Res.1). Dikdörtgen prizma gövdeli çeşme betonarme kademeli bir platform üzerinde yükselmektedir (Şek1,2). Bu platform, 1984 yılında çeşmenin taşınması esnasında yapılmış olmalıdır. Orijinalinde çeşmenin sadece ön cephesi işleve yönelik tasarlansa da arka cephede de muhtemelen 1984 yılında tekne yerleştirilerek bu cepheye de işlev kazandırılmıştır.

Yapının yola bakan ana cephesi diğer cephelere göre daha özenli tasarlanmıştır. Cephe ortasında derinliği fazla olmayan sivri kemerli çeşme nişi yer almaktadır (Res.2). Niş, kemer üzengi noktası alt hizasından yatay bir frizle iki bölüme 
ayrılarak kemer alınlığının içerisine çiniler yerleştirilmiş̧ir. Friz altında ise dikdörtgen formlu yekpare ayna taşı üzerinde dikdörtgen formlu çeşme oluğu, bu oluğun iki yanında da kaş kemerli nişler konumlandırılmıştır.

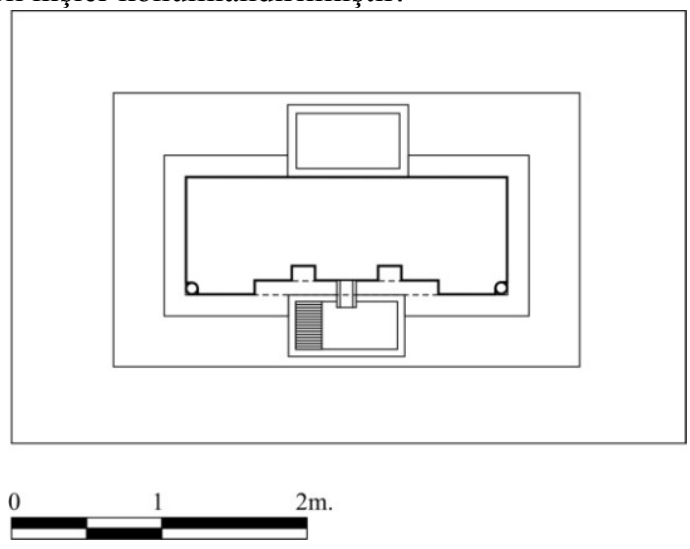

Şek.1- Ödemiş-Bozdağ yolu, Paşa Çeşmesi, plan.

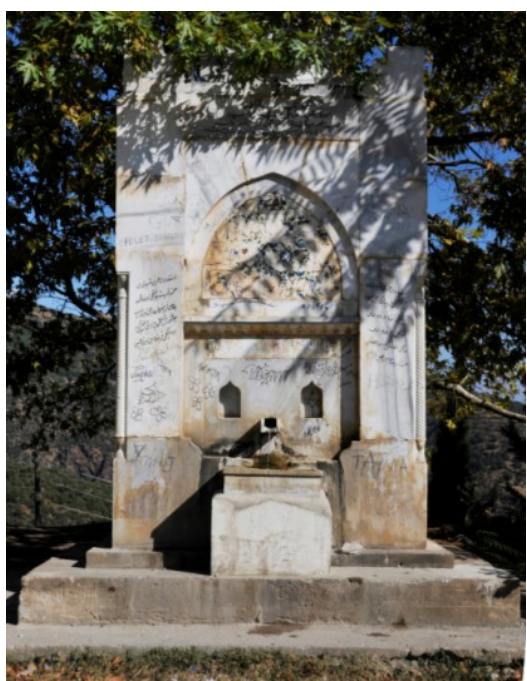

Res.2- Paşa cephesi, ön cephe.

Ön cephede kademeli platform üzerinde yükselen dışa taşıntılı betonarme altlık üzerinde mermer tekne yer almaktadır. Cephe yan kanatları sütuncelerle sınırlandırılmıştır. Ön cephe profilli tepelikler ve tepelikler arasına yer alan 1984 yılındaki taşınmaya ilişkin dikdörtgen formlu kitabe levhası ile sonlandırılmıştır.

Yapının yan cephelerinde herhangi bir çeşme elamanı mevcut değildir. Bu cepheler sade bırakılmıştır. Çeşmenin arka cephesi ön cepheye göre oldukça sadedir (Res.4). Bu cephenin ortasında, ön cephedeki ile hemen hemen aynı boyutlara sahip mermer bir tekne mevcuttur. Yalağın hemen üst kısmında sonraki bir dönemde kapatılmış olduğu anlaşılan bir oluğun izi görülmektedir. Bu cephenin büyük bir bölümünde ön cephedeki kitabelerin Latin harfleri ile çevirilerinin yer aldığ 1 kitabe panoları bulunmaktadır.

Yapının üzerine oturduğu kademeli platform betonarme, çeşme cepheleri ise mermer kaplamalıdır. Çeşme asal unsurlarını oluşturan tekneler ve oluk da mermer malzemelidir. 


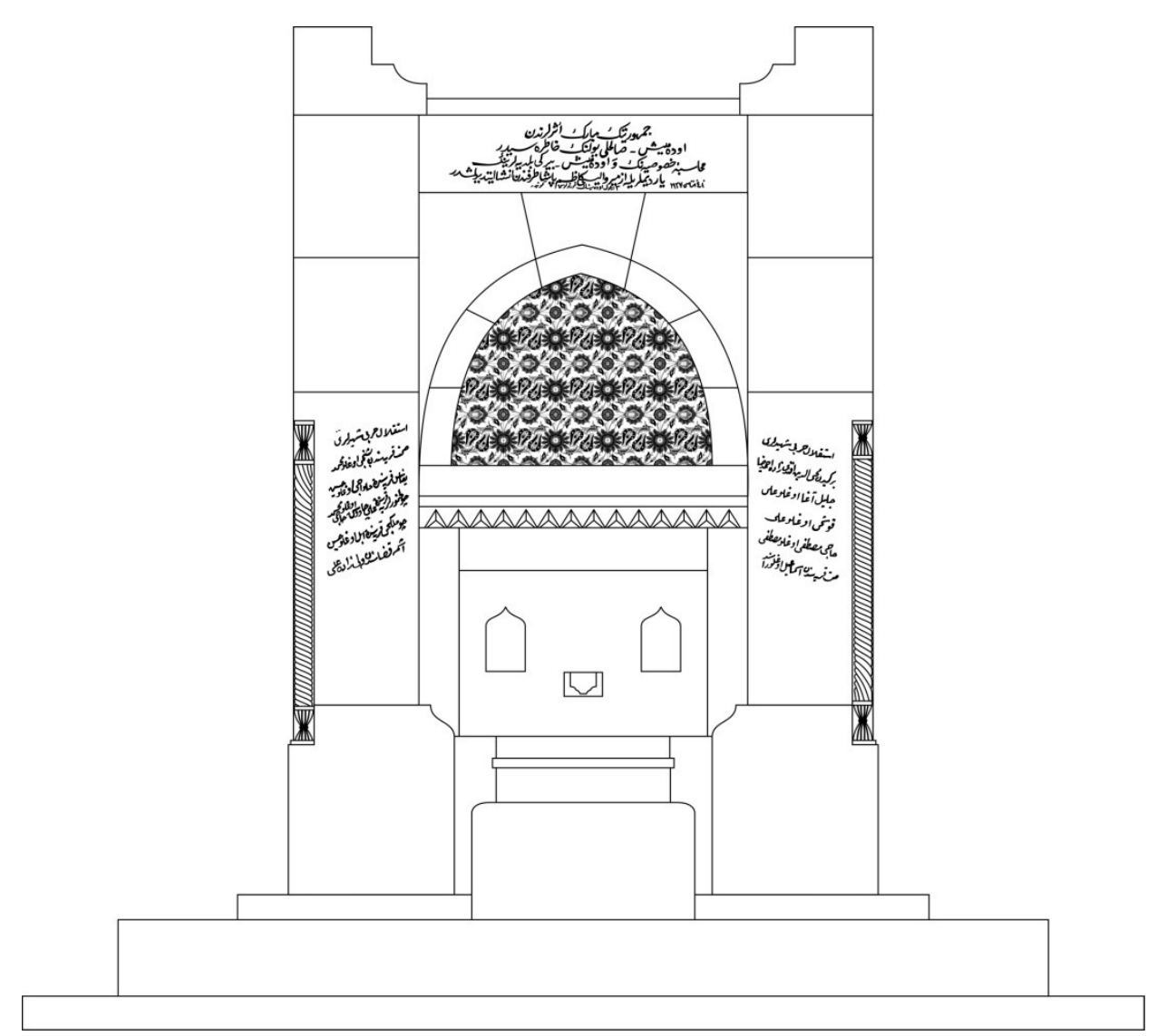

Şek.2- Ödemiş-Bozdağ yolu, Paşa Çeşmesi, ön cephe.

Çeşmedeki bezemeler ön cephede dikkati çekmektedir. Ayna taşı ile sivri kemerli alınlığın arasına mukarnas dişlerinden oluşan bir friz yerleştirilmiştir. Ana cephenin köşelerinde yivlendirilmiş kum saati şeklinde başlıklara sahip burmalı birer sütunce yer almaktadır. Cephe üstünde köşelikler arasında yer alan 1984 tarihli levhada ise ay-yıldız motifleri görülmektedir.

Sivri kemerin içi, kemer formuna uygun olarak yerleştirilen beyaz hamurlu beyaz astarlı ve şeffaf sırlı Kütahya çinileri ile doldurulmuştur (Res.3). Büyük bir bölümü tahrip olmuş çinilere dikkatlice bakıldığında beyaz zemin üzerine sarı, yeşil, mavi ve kırmızı renklerle dolgulandırılmış bitkisel motiflere sahip ulama bir kompozisyon olduğu görülebilmektedir. Kompozisyonu bütünleyen karolardan her birinde, karonun dört köşesinde $1 / 4$ oranında verilmiş stilize birer penç bulunmaktadır (Şek.3). Karonun kenar ortalarına ise karşılıklı olarak birbirlerinin aynısı olan 1/2 oranında verilen birer hatai yerleştirilmiştir. Kenarlar üzerindeki hatailer dairesel hatlı 
sapla birbirlerine bağlanmıştır. Karşılıklı iki kenar üzerindeki hatailerin sap kısmından çıkan iki dal ise helezonik kıvrım yaparak ortada birer lale ile sonlandırılmıştır. Lale motiflerinin içleri küçük çiçeklerle doldurulmuştur. Çini karolar hep aynı yöne bakacak şekilde yan yana yerleştirildiğinde, köşelerdeki çeyrek, kenarlardaki yarım motifler birbirlerini tümleyerek kompozisyonun ${ }^{2}$ devamlılığı sağlanmaktadır (Şek.4). Ancak bu çeşmede çinilerin bazı sıralarda sapmalara uğradığı, motiflerin birbirlerini tam olarak tümleyemediği görülmektedir (Şek.5).
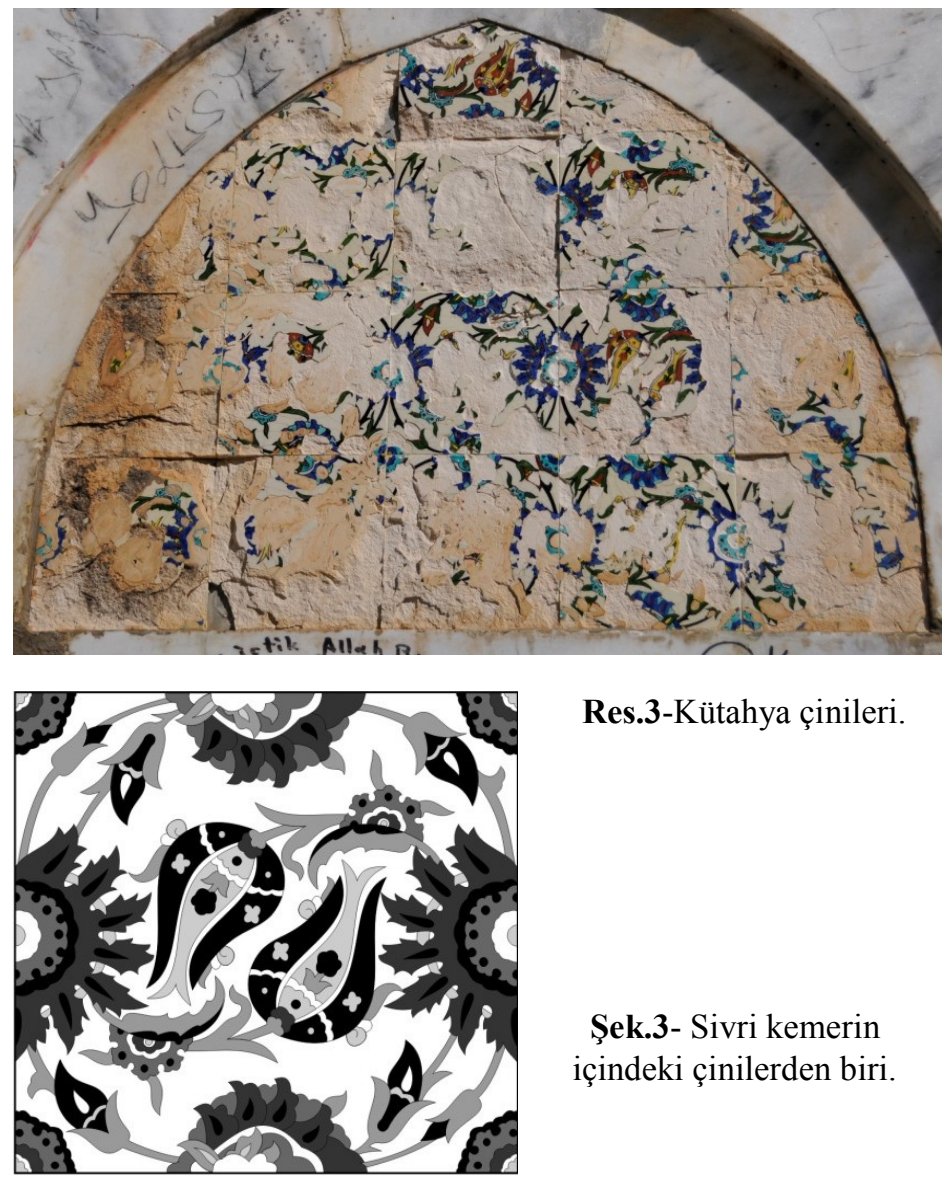

Res.3-Kütahya çinileri.

Şek.3- Sivri kemerin içindeki çinilerden biri.

${ }^{2}$ Bu tür kompozisyonlar Turan Bakır tarafından "Dairesel Hatlı Ulama Kompozisyonlar" olarak adlandırılmaktadır. Bilgi için bkz. Turan Bakır,1999, 221-222. 


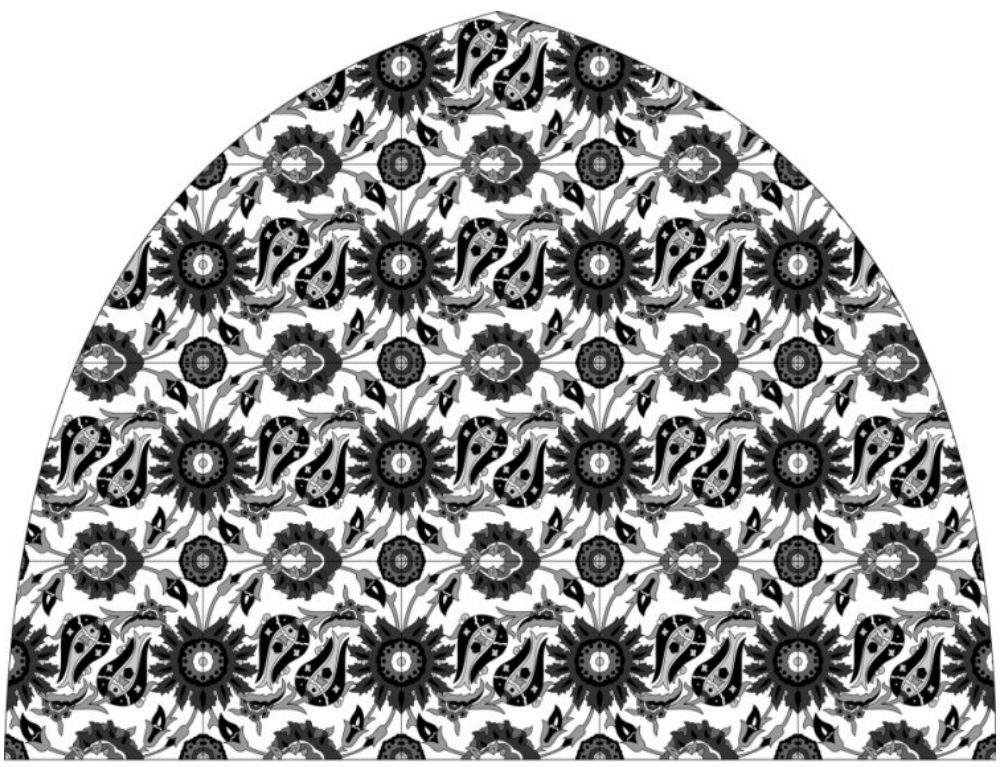

Şek.4- Sivri kemerin içindeki çinilerin restitüsyonu.

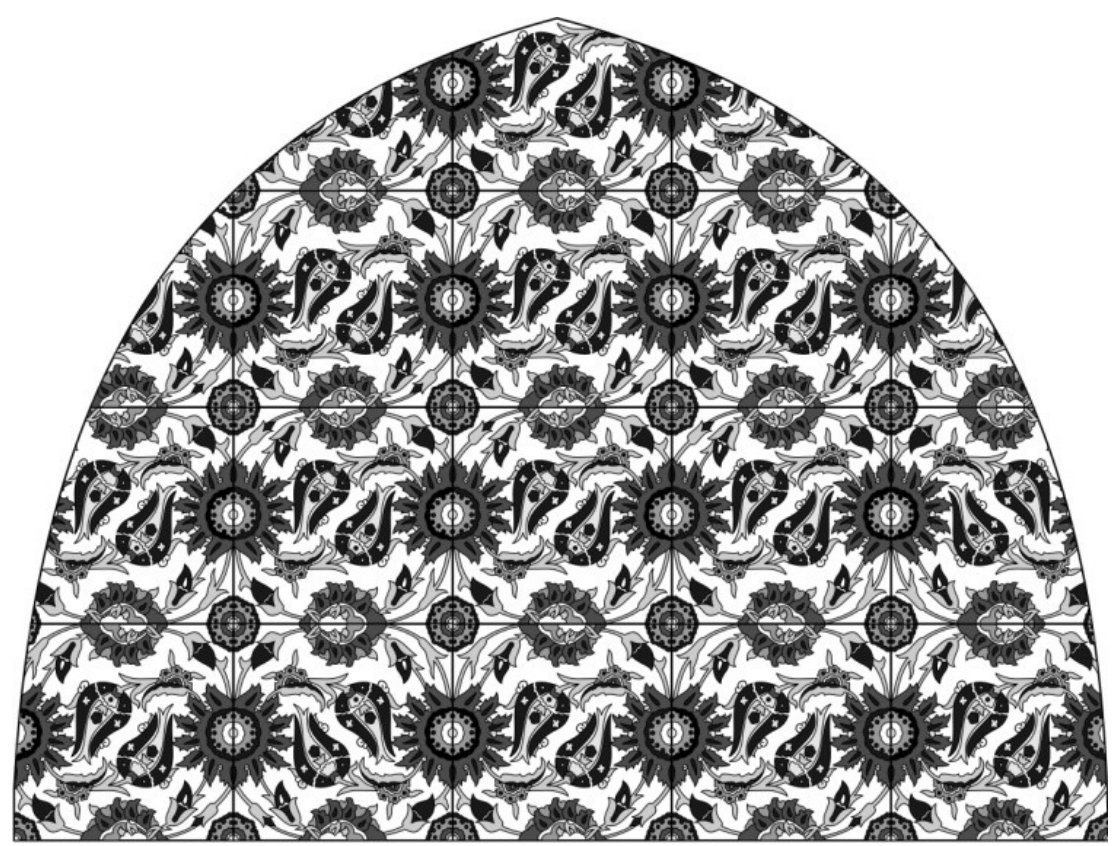

Şek.5- Sivri kemerin içindeki çinilerin mevcut durumunun restitüsyonu 
Ana cepheyi diğer cephelerden farklı kılan özelliklerden birisi de cephedeki yazıtların çokluğudur. Sütunceler ile çeşme nişi arasında kalan boşluklarda kitabeler olduğu görülmektedir (Şek. 6,7). Kitabelere İstiklal Harbi şehitlerinin isimleri yazılmıştır.
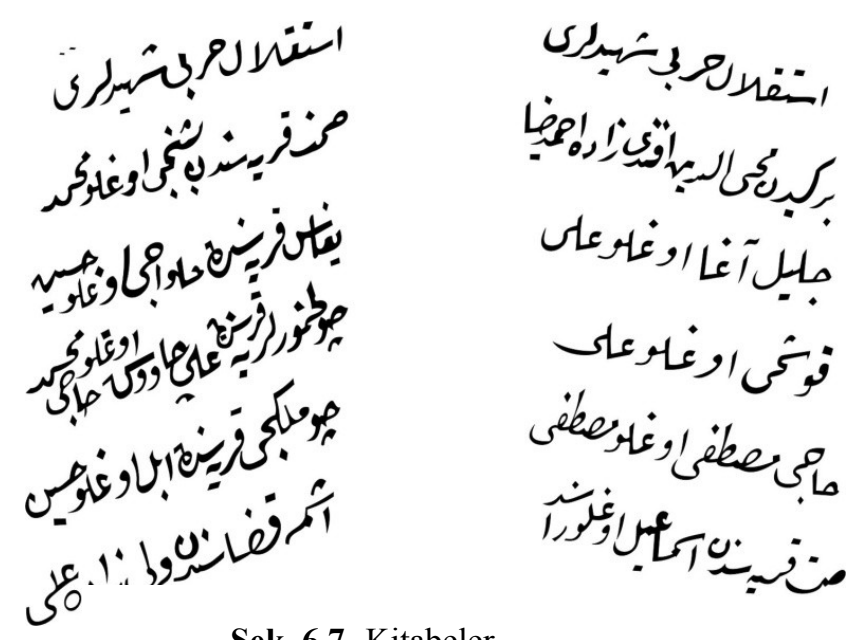

Şek. 6,7- Kitabeler

Cephenin sağ tarafinda bulunan kitabenin transkripsiyonu şu şekildedir:

Istiklal Harbi Şehidleri

Birgi'den Muhiddin Efendi ${ }^{3}$ zade Ahmed Ziya

Celil Ăga oğlu Ali

Kuşcu oğlu Ali

Hacı Mustafa oğlu Mustafa

Semit karyesinden İsmail oğlu Raşid ${ }^{4}$

Cephenin sol tarafinda bulunan kitabenin metni şu şekildedir:

İstiklal Harbi Şehidleri

${ }^{3}$ Bu kelime çeşme arka cephesinde yer alan çeviri de eksik yazılmıştır.

41890 doğumlu İsmail oğlu Raşit, Çanakkale cephesinde 4. Kolordu, 30. Alay, 1. Tabur, 1. Bölükte görev yaparken 26.05.1331/8 Haziran 1915 yılında Sığındere'de şehit olmuştur. http://www.msb.gov.tr/arsiv/phpscr/SehitlerDetay.php?Sira=99833.26.3.2014 
Seyit karyesinden Beşinci oğlu Mehmed

Yefes $?^{5}$ karyesinden Helvacı oğlu Hüseyin

Çulhamurlar karyesinden Ali Çavuş oğlu Hacı Mehmed

Çömlekci ${ }^{6}$ karyesinden Ebil ${ }^{7}$ ? oğlu Hüseyin

Eşme kazasından Veli zade Ali

Çeşmenin üst kısmında yatay dikdörtgen şekilli inşa kitabesi yer almaktadır (Res.4, Şek.8 ). Kitabenin transkripsiyonu şu şekildedir:

Cumhuriyetin mübarek eserlerinden

Ödemiş-Salihli yolunun hatırasıdır

Muhasebe-i hususiyenin ve Ödemiş-Birgi belediyelerinin

yardımlarıyla İzmir valisi Kazım Paşa tarafindan inşa ettirilmiştir.

Tarih-i inşası 19273 Eylül Ödemiş’in kurtuluş günüdür.

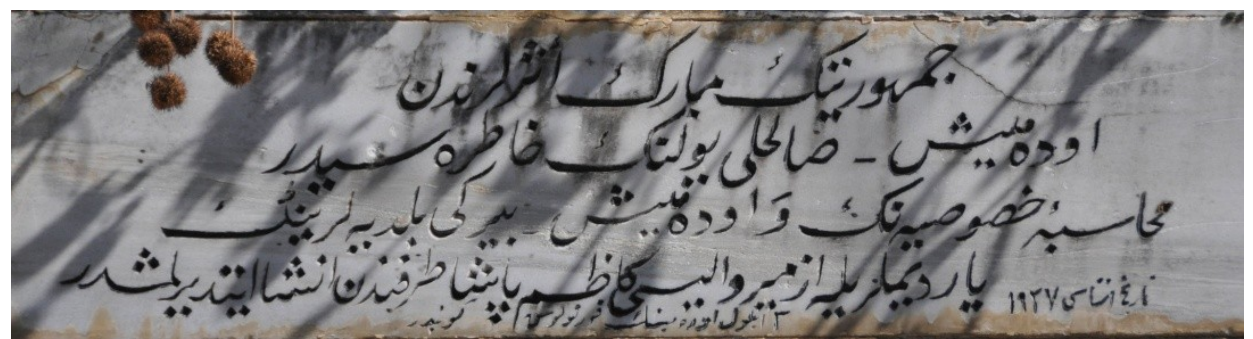

Res.4- İnşa kitabesi

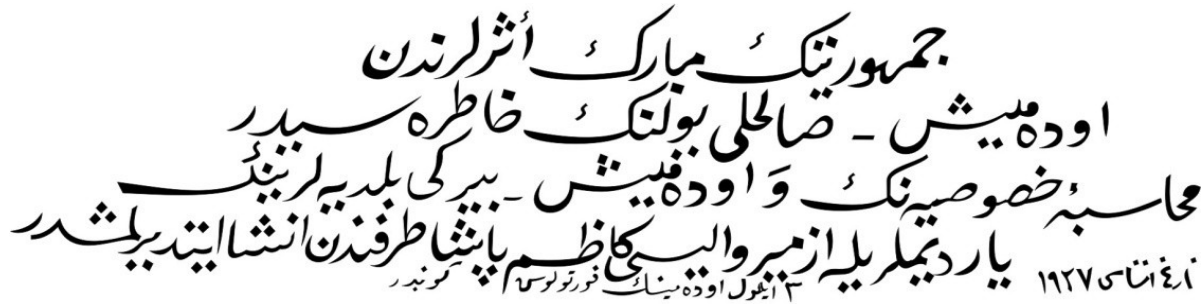

Şek.8- İnşa kitabesi

${ }^{5}$ Çeşme arka cephesinde yer alan çeviride "Yefes" adı geçse de 1530 tarihli defterde "Yağas" adı da geçmektedir. Bkz., Yavuz, 2011, 163.

${ }^{6}$ Çeşme arka cephesindeki çeviride "Çömlekciler" olarak yazılmıştır.

${ }^{7}$ Bu kelime arka cephedeki panoda "Ebil” olarak yazılmıştır. Milli Savunma Bakanlığ 1 kayıtlarına göre Tire doğumlu Habil oğlu Hüseyin'in Çanakkale cephesinde 12.06.1331/ 8 Haziran 1915 tarihinde şehit olduğu anlaşılmaktadır. Bu kelimenin "Habil" olması da muhtemeldir. 
Kitabeden, Paşa Çeşmesi'nin, Cumhuriyet anısına Ödemiş ve Birgi belediyelerinin yardımlarıyla 1927 yılında İzmir Valisi Kazım Paşa tarafından yaptırıldığı anlaşılmaktadır.

Çeşme, üstte iki yandan dekoratif iç kenara sahip birer blok taş ile sınırlandırılmıștır. $\mathrm{Bu}$ blok taşların arasında Latin harfleriyle yazılmış bir levha bulunmaktadır ${ }^{8}$ (Res.5). Yazı şu şekildedir:

\section{Paşa Çeşmesi}

$\mathrm{Bu}$ tarihi çeşme 1927 yılında Kurtuluş Savaşı

Kumandanlarından İzmir Valisi Kazım Dirik Paşa

tarafindan yaptırılmıştır.

Çeşme 1984 yılında Ödemiş Kaymakamı Erdoğan

İzgi’nin öncülüğünde Adapazarlı İsmet Uzman Kış-

lalı Hasan Güçlü'nün maddi ve manevi desteği kara-

yollarının müzahareti ile yeni yol güzergahı olan

buraya nakledilerek tekrar ihyası sağlanmıştır

5 Temmuz 1984.

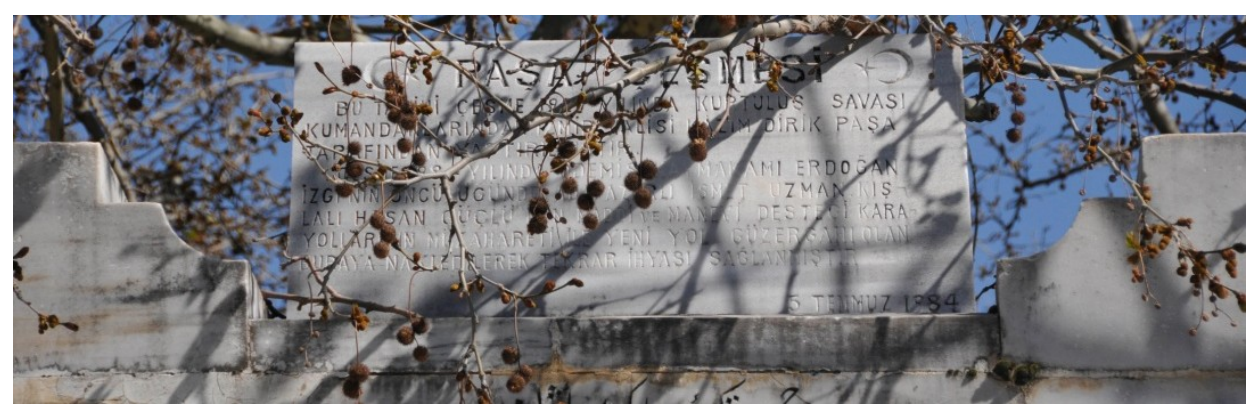

Res.5- Kitabe levhas1

Bu levhadan hareketle 1927 yılında Kazım Dirik tarafindan inşa ettirilen çeşme yol genişletme çalışmaları nedeniyle 1984 yılında şimdiki konumuna taşınmışıtır.

${ }^{8}$ Çeşmeye ait 1985 tarihli bir fotoğrafta bu yazı levhasının bulunmadığı görülmektedir. Fotoğraf için bkz. Altınoluk, 1987, 24.

9 1981-86 yılları arasında Ödemiş kaymakamı olarak görev yapmıştır. http://www.odemis.gov.tr/default_b0.aspx?content=1034 
Ödemiş-Bozdağ yolu üzerinde bulunan ve herhangi bir yapıdan bağımsız olarak duran Paşa Çeşmesi, I. Ulusal Mimarlık Dönemi yapılarının temsilcilerinden biridir. Ulusal bir bilinç yaratılmak için geçmiş değerlerin kullanılması gerektiğinin savunulduğu 1908-1930 yılları arasını kapsayan dönem I. Ulusal Mimarlık Dönemi olarak adlandırılmaktadır ${ }^{10}$. Z. Gökalp'in Türkçülük tanımı ${ }^{11}$ etkileri ile bu dönem ekonomi, siyaset, dil, din gibi konularda olduğu gibi mimaride de ulusal bilinç yaratılmaya çalışılmıştır. I. Ulusal Mimarlık Dönemi'nde özellikle dış cephe tasarımları önem kazanmış, Selçuklu ve Osmanlı dönemlerinde kullanılan kemerler, pencere, saçak, kubbe, sütun, madeni bezemeler ve çini panolar sıkça kullanılmıştır ${ }^{12}$. Çini panolarda 16. yüzyıl İznik çinilerinin motifleri yeniden ele alınmış, Kütahya çiniciliği yeniden canlandırılmaya çalışılmışıır ${ }^{13}$. Bu öğeler, kütüphane, halkevi, sinema, banka, iş hanı, konut gibi birçok farklı yapıda yer aldığı gibi, çeşme cephelerini de süslemiş̧tir. 1927 tarihinde yaptırılan Ödemiş- Bozdağ yolu üzerindeki Paşa Çeşmesi de, köşelerde kullanılan sütunları, sivri kemerliği alınlığı, alınlığın içini süsleyen Kütahya çinileri gibi öğeleriyle I. Ulusal Mimarlık Dönemi mimari özelliklerini taşımaktadır. Çeşme, cephesinin çinilerle süslenmesi açısından Kütahya Ahi Evren Çeşmesi (1916-17) ${ }^{14}$, Kütahya Çinili Çeşme (1952) ${ }^{15}$, Manisa Zahide Hanım Çeşmesi (1918-19) ${ }^{16}$, Bursa Ulu Cami Çeşmesi ${ }^{17}$ ile benzerlikler göstermektedir.

Ödemiş-Bozdağ yolu Paşa Çeşmesi'ni süsleyen Kütahya çinilerinde 16. yüzyıldan beri kullanılan lale, hatai, penç gibi motifler bulunmaktadır. Çini karoların köşelere yerleştirilen çeyrek, kenarlara yerleştirilen yarım motiflerin spiral kıvrımlı dallarla birbirlerine bağlandığı dairesel hatlı ulama kompozisyonlar 16. yüzyılın ikinci yarısından itibaren sıklıkla tercih edilmiştir. Benzer komposizyona sahip İstanbul Ramazan Efendi Camii (1586) ${ }^{18}$ ve Topkapı Sarayı III. Murad Odası $(1578)^{19}$ çinilerinde kıvrımdalar birer yaprakla sonlandırılmıştır.

${ }^{10} \mathrm{Bu}$ dönemin başlama ve bitiş tarihleri konusunda değişik görüşler bulunmaktadır. Bu görüşler hakkında ayrıntılı bilgi için bkz. Sözen ve Tapan, 1973, 99; Aslanoğlu, 1980, 13; Yavuz, 1981, 6.

${ }^{11}$ Ziya Gökalp'in görüşleri için bkz. Gökalp, 2013.

${ }^{12}$ Sözen, 1996, 17; Aslanoğlu, 1-25.

${ }^{13}$ Kütahya çiniciliğinin canlandırılması konusunda daha geniş bilgi için bkz. Aslanapa, 1949, 113.

${ }^{14}$ Şahin,1981-82, 135,168,Res.57-58; Altun, 1981-82, 443, 697, Res.71/12

${ }^{15}$ Şahin, 1981-82, 136,169, Res.59-60.

${ }^{16}$ Uçar,2012, 142-145.

${ }^{17}$ Yetkin, 1981-82, 92.

${ }^{18}$ Çizim için bkz. Batur, 1958, 179.

${ }^{19}$ Fotoğraf için bkz. Turan Bakır,1999, 285.

\section{Sanat Tarihi Dergisi}


Paşa Çeşmesi alınlığını süsleyen çinilerinin aynı kompozisyona sahip farklı renkli örnekleri günümüzde Kütahya Evliya Çelebi Çini Fabrikası tarafından "EÇ. 207 $20 X 20 \mathrm{~cm}$. toplu çini karo" adıyla üretilmektedir ${ }^{20}$.

Yazımızın başında da bahsettiğimiz gibi, Ödemiş-Bozdağ yolu üzerindeki Paşa Çeşmesi İzmir Valisi Kazım Dirik tarafından yaptırılmıştır. İzmir’de 1926-1935 yılları arasında valilik yapan Dirik “Ayrancı Paşa” lakabıyla da tanınmaktadır. Eğitime önem veren Paşa'nın, valiliği sırasında gerek İzmir merkezinde, gerekse İzmir' in ilçelerinde ve köylerinde çok sayıda okul, okuma salonu açılmış, kredi kooperatifleri kurulmuş, çocuk oyun alanları, parklar yapılmış, köyleri İzmir'e bağlayan yollar açılmış ve halk suyla buluşturulmuştur. Kültürpark, Şirinyer Hipodromu, Cumhuriyet Meydanı'ndaki Atatürk heykeli gibi birçok önemli eserin açılmasını da sağlayan Paşa 1941 yılında hayatını kaybetmiştir. İzmir'i ve İzmirli'yi seven Paşa'yı ölümünden sonra İzmirliler de unutamamış, bir caddeye Vali Kazım Dirik adı verilip, buraya bir de valinin büstü dikilerek adı yaşatılmıştır ${ }^{21}$.

\section{KAYNAKÇA}

Altınoluk, Ü.( 1987). Ödemiş Çeşmeleri, İlgi, 48, İstanbul, 24-28.

Altun, A.(1981-82), "Kütahya'nın Türk Devri Mimarisi” "Bir Deneme”, Atatürk’ün Doğumunun 100. Yllına Armağan, İstanbul:

Aslanapa, O. (1949), Osmanlılar Devrinde Kütahya Çinileri, Üçler Basımevi: İstanbul.

Aslanoğlu, İ. (1980), Erken Cumhuriyet Dönemi Mimarlı̆̆l, O.D.T.Ü. Mimarlık Fakültesi Basım İşliğii: Ankara.

Batur, M. (1958). Ramazan Efendi Camii, Arkitekt, 1958-04, 176-180.

Dirik, K. O. (2008). Atatürk’ün İzinde Vali Paşa Kazım Dirik (Bandırma Vapuru'ndan Halkın Kalbine), Gürer Yayınları: İstanbul.

Dirik, O. (1998). Babam Kazım Dirik ve Ben, Yapıkredi Yayınları: İstanbul.

Eyice, S. (1993). Çeşme, Türkiye Diyanet Vakfı İslam Ansiklopedisi, 8, İstanbul, 284-287.

Gökalp, Z. (2013). Türkçülüğün Esasları, Bilgeoğuz Yayınları: İstanbul.

Keskin, M. A. (1992). İzmir Valileri (Kuruluşa Kadar Aydın Valileri 13901992), Memleket Matbacılık: İzmir.

20 Bkz. http://www.evliyacelebicini.com.tr/tr/evliya-celebi-cini-cami-cini-karosu $\quad 10.02 .2014$ 15.15

${ }^{21}$ Kazım Dirik hakkında daha fazla bilgi için bkz. Keskin, 1992, 84-86; Dirik, 2008 
Sözen, M. (1996), Cumhuriyet Dönemi Türk Mimarisi, Türkiye İş Bankas1 Kültür Yayınları: İstanbul.

Sözen, M.-Tapan, M. (1973). 50 Yllın Türk Mimarisi, İş Bankası Kültür Yayınları: İstanbul.

Şahin, F.(1981-82), “Kütahya'da Çinili Eserler”, Atatürk'ün Doğumunun 100. Yılına Armăgan, İstanbul, 111-170.

Tanışık, İ. H. (1945). İstanbul Çeşmeleri, Eski Eserler ve Müzeler Umum Müdürlüğü Yayınları: İstanbul.

Turan Bakır, S. (1999). “İznik Çinilerinde Ulama Karo Tasarımları”, Osmanll, (Edt. Güler Eren), XI, Ankara, 220-226.

Uçar, H.(2012), Sipil'den Manisa'ya Ab-ı Hayat Manisa Çeşmeleri, Manisa.

Yavuz, B.G.(2011), Birgi, Coğrafyası, Halk Bilgisi, Tarihçesi, Tarihi Yerleri "The History of Birgi", İzmir.

Yavuz, Y. (1981). Mimar Kemalettin ve I. Ulusal Mimarlık Dönemi, O.D.T.Ü. Mimarlık Fakültesi Basım İşliği: Ankara.

Yetkin, Ş.(1981-82), "Kütahya Dışındaki Kütahya Çinileri ile Süslü Eserler”, Atatürk'ün Doğumunun 100. Yılına Armă̆an, İstanbul: 83-110.

http://www.msb.gov.tr/arsiv/phpscr/Sehitler.php.24.3.2014

http://www.evliyacelebicini.com.tr/tr/evliya-celebi-cini-cami-cini-karosu10.02.2014 15.15

http://www.odemis.gov.tr/default_b0.aspx? content=1034.24.3.2014 